\title{
Electrodeposition of Cobalt Based Ferro-magnetic Metal Nanowires in Polycarbonate Films with Cylindrical Nanochannels Fabricated by Heavy-Ion-Track Etching
}

T. Ohgai ${ }^{1,3}$, K. Hjort ${ }^{2}$, R. Spohr ${ }^{1}$ and R. Neumann ${ }^{1}$

1: Gesellschaft für Schwerionenforschung (GSI), D-64291 Darmstadt, Germany

2: The Ångström Laboratory, Uppsala University, Box 534, S-75121 Uppsala, Sweden

3: Faculty of Engineering, Nagasaki University, Nagasaki 852-8521, Japan

(E-mail: ohgai@nagasaki-u.ac.jp, Tel/Fax: +81-95-819-2638)

\begin{abstract}
Polycarbonate films of thickness $30 \mu \mathrm{m}$ were irradiated with heavy ions by applying a flux of $10^{8}$ ions $\mathrm{cm}^{-2}$ to produce straight tracks perpendicular to the film surface. The tracks were preferentially etched in $6 \mathrm{M}$ aqueous solution of sodium hydroxide to prepare cylindrical nanochannels. The channel diameters were tuned between $200 \mathrm{~nm}$ and $600 \mathrm{~nm}$ by varying the etching time. $\mathrm{Co}_{81} \mathrm{Cu}_{19}$ alloy nanowires were electrodeposited potentiostatically, while $\mathrm{Co} / \mathrm{Cu}$ multi-layered nanowires, consisting of alternating $\mathrm{Co}$ and $\mathrm{Cu}$ layers with thickness $10 \mathrm{~nm}$, were synthesized by means of a pulse plating technique in channels of length $30 \mu \mathrm{m}$ and diameter $200 \mathrm{~nm}$. $\mathrm{Co}_{81} \mathrm{Cu}_{19}$ alloy nanowires showed an anisotropic magnetoresistance effect of $0.6 \%$, and the giant magnetoresistance of $\mathrm{Co} / \mathrm{Cu}$ multilayered nanowires reached up to $8.0 \%$.
\end{abstract}

(Keywords: heavy ion, polycarbonate, electrodeposition, cobalt, copper, nanochannel) 


\section{INTRODUCTION}

Nanosized materials such as nanotubes, nanowires, and nanoparticles show novel physical and chemical properties on the basis of finite-size and quantum-effects. Among nanosized materials, nanowires are promising candidates as pioneering electron transport materials, applicable to magnetoresistive and optoelectronic devices in ultra-large-scale integration (ULSI). Nanowires can be grown by electrodeposition from aqueous solution into nanochannel templates [1-3] such as commercially available polycarbonate membranes [4-6] or anodized porous alumina membranes [711]. In commercial polycarbonate membranes, the nanochannels are distributed at random. Similarly, the angles between the channel axis and the film normal vary up to more than 10-20 degrees. The shape of these nanochannels is also far from an ideal cylinder. In anodized aluminum oxide films, inter-channel distance is less than the channel-diameter and typically below $100 \mathrm{~nm}$. This makes lithography very difficult when only a few wires are to be coupled in a magnetoresistive device to give it high enough resistance and hence enhance its applicability. Furthermore, the oxide film is chemically unstable, e.g. dissolvable in acidic or alkaline aqueous solutions. Template synthesis techniques using nanochannel polymer films can be applied to fabricate nanosized electronic devices in ULSI. To realize the integration of this technique and microelectronics in ULSI, the size parameters such as channel length, channel diameter, and inter-channel distance must be controlled over a wide range. Lithographic Galvanoforming (LIGA) using energetic heavy ion beams can be applied to the polymer template synthesis. Using a modified heavy-ion LIGA technique, we have reported the fabrication of homogeneous $\mathrm{Ni}$ and Co nanowires with a wide range of aspect ratios in polycarbonate and polyimide films [12].

In a recent study $\mathrm{Co} / \mathrm{Cu}$ nanowires grown in porous alumina membranes have shown high Giant Magneto Resistance (GMR) values [11]. In this study, to ease the production of magnetoresistive devices of high resistance, we aim at synthesizing $\mathrm{Co} / \mathrm{Cu}$ wires in a polymer template employing the modified heavy-ion LIGA technique. Here a polycarbonate film was irradiated with energetic heavy ions [13-18] to produce straight tracks $\left(10^{8}\right.$ ions $\left.\mathrm{cm}^{-2}\right)$, and subsequently the film was 
preferentially etched attacking the tracks to realize cylindrical nanochannels with an aspect ratio larger than $100 . \mathrm{Co}_{81} \mathrm{Cu}_{19}$ alloy nanowires and $\mathrm{Co} / \mathrm{Cu}$ multilayered nanowires were electrodeposited in the template with channels of length $30 \mu \mathrm{m}$ and diameter $200 \mathrm{~nm}$. The Anisotropic Magneto Resistance (AMR) effect of $\mathrm{Co}_{81} \mathrm{Cu}_{19}$ alloy nanowires as well as the GMR effect of $\mathrm{Co} / \mathrm{Cu}$ multilayered nanowires was investigated.

\section{EXPERIMENTAL}

Figure 1 illustrates the fabrication process of $\mathrm{Co} / \mathrm{Cu}$ multilayered nanowires electrodeposited in nanochannels obtained by the heavy-ion track etching technique applied in this study: (a) recording of heavy ion tracks, (b) etching of tracks, (c) formation of electrodes, (d) electrodeposition of Co/Cu nanowires. Polycarbonate films with a thickness of $30 \mu \mathrm{m}$ were used as templates. First, by irradiating the sample with an ion beam from the UNILAC linear accelerator (GSI, Darmstadt, Germany), straight ion tracks with a density of $10^{8}$ tracks $\mathrm{cm}^{-2}$ were created perpendicular to the film surface as shown in Fig.1(a). The tracks were selectively etched in a 6 M aqueous solution of $\mathrm{NaOH}$ to produce cylindrical nanochannels as depicted in Fig.1(b). The etching process following the irradiation was optimized to produce a uniform cross section all along the channel with very small roughness. A copper layer of thickness $1 \mu \mathrm{m}$, which acts as cathode for the nanowire growth, was electrodeposited on a gold layer of thickness $100 \mathrm{~nm}$ sputtered on the membrane as shown in Fig.1(c). An aqueous electrolytic solution was synthesized from $\mathrm{CoSO}_{4} \bullet 7 \mathrm{H}_{2} \mathrm{O} 120 \mathrm{~g} \mathrm{~L} \mathrm{~L}^{-1}$, $\mathrm{CuSO}_{4} \bullet 5 \mathrm{H}_{2} \mathrm{O} 1.6 \mathrm{~g} \mathrm{~L}^{-1}$ and $\mathrm{H}_{3} \mathrm{BO}_{3} 45 \mathrm{~g} \mathrm{~L}^{-1}$ for electrodeposition of Co-Cu alloy nanowires and $\mathrm{Co} / \mathrm{Cu}$ multilayered nanowires. A cathodic polarization curve was measured over a wide range of cathode potential to determine the optimum potential for $\mathrm{Cu}$ and Co deposition. Growth rates of nanowires were estimated by the channel filling time, which was determined from the time dependence of deposition current at each potential. $\mathrm{Co} / \mathrm{Cu}$ multilayered nanowires were electrodeposited by alternatingly changing the cathode potential from $-0.3 \mathrm{~V}$ vs. $\mathrm{Ag} / \mathrm{AgCl}$ (for $\mathrm{Cu}$ layer) to $-1.0 \mathrm{~V}$ (for Co layer) as shown in Fig.1(d). To determine the alloy composition of the 
wires, a sample was prepared as follows. First, nanowires were electrodeposited at constant cathode potential in polycarbonate channels with length $30 \mu \mathrm{m}$ and diameter $200 \mathrm{~nm}$. Then, the polycarbonate was dissolved in an organic solvent to expose the wires. Finally, the wire composition was determined by EDX. Co-Cu alloy nanowires electrodeposited at $-1.0 \mathrm{~V}$ contained 81\%-Co and 19\%-Cu. To measure the wire resistance the wires were in-situ contacted with a gold layer during the electrodeposition process as illustrated in Fig.1(d). Magneto-resistance curves were measured at room temperature applying a direct current of $10 \mu \mathrm{A}$ and changing the magnetic field up to $10 \mathrm{kOe}$.

\section{RESULTS AND DISCUSSION}

\subsection{Fabrication of Nanochannels}

Figure 2 shows the effect of film thickness on the monitoring current during etching of the heavyion tracks in polycarbonate films with thicknesses 10, 30, and $60 \mu \mathrm{m}$. During etching, a constant voltage ( $1 \mathrm{~V}$ ) was applied between two gold electrodes separated by the membrane in $6 \mathrm{M}$ aqueous $\mathrm{NaOH}$. The time dependence of the resulting current between the electrodes is displayed in Fig.2. At the beginning of the etching, a very small current of the order of $10^{-11} \mathrm{~A}$ was observed, corresponding to a huge resistance $\left(10^{11} \Omega\right)$ measured between the electrodes. This resistance is due to the still unetched polycarbonate. The current increases drastically at an etching time of about 300 sec when using the polycarbonate film with thickness $30 \mu \mathrm{m}$. At this break-through time, the channels reach the perforated state. After break-through, the current increases up to roughly $10^{-2} \mathrm{~A}$, and a small resistance $\left(10^{2} \Omega\right)$ is measured between the electrodes. Figure 3 represents the relationship between polycarbonate film thickness and break-through time. As shown in this figure, with increasing film thickness, the break-through time also increases and the etching rate is estimated to be around $50 \mathrm{~nm} \mathrm{~s}^{-1}$. Apel et al. reported etching rates of the order of 20 and $50 \mathrm{~nm} \mathrm{sec}^{-}$

1 for single ion tracks in semicrystalline polycarbonate film with thickness 10 and $30 \mu \mathrm{m}$, respectively [19]. Chtanko et al. also reported that the etching rate of single ion tracks in 
semicrystalline polycarbonate film with thickness $20 \mu \mathrm{m}$ was circa $50 \mathrm{~nm} \mathrm{~s}^{-1}$ [20]. The result obtained in this study corresponds well to the data reported in [19, 20].

Figures 4(a)-(d) display SEM images of etched nanochannels in polycarbonate films with thickness $30 \mu \mathrm{m}$ obtained at etching times of 1,000, 1,500, 2,000, and 3,000 s, respectively. Each sample was sputter-coated with a thin gold layer to avoid electro-charging effects during SEM observation. The channel diameter increases with increasing etching time and the distribution of the channel diameters is quite narrow. Figure 5 shows the time-dependence of channel diameter (a), channel cross-sectional area (b), and current (c) measured during track etching in the polycarbonate film with thickness $30 \mu \mathrm{m}$. As a function of etching time, the channel diameter increases as shown in Fig.5(a). The diameter can be tuned between 200 and $600 \mathrm{~nm}$ by varying the etching time. After $1,000 \mathrm{~s}$, the diameter is estimated to be around $200 \mathrm{~nm}$. The channel diameter $D_{\mathrm{t}}(\mathrm{nm})$ at etching time $t$ (s) can be estimated as follows.

$$
D_{\mathrm{t}}=0.20 t
$$

Here, $t$ (s) is larger than the break-through time of $300 \mathrm{~s}$. The radial etching rate is estimated to be circa $0.10 \mathrm{~nm} \mathrm{~s}^{-1}$, and a channel diameter down to $60 \mathrm{~nm}$ could be obtained in this experimental condition. Apel et al. reported a radial etching rate of about $0.1 \mathrm{~nm} \mathrm{~s}^{-1}$ for heavy ion tracks in polycarbonate films with thicknesses $10 \mu \mathrm{m}$ [19]. Pépy et al. also reported that the radial etching rate in such films with thicknesses $20 \mu \mathrm{m}$ was around $0.2 \mathrm{~nm} \mathrm{~s}^{-1}$, respectively [21]. These data agree well with the result obtained in this study. As shown in Fig. 5(b) and Fig. 5(c), the time-dependence of the cross-sectional area corresponds well to the time dependence of measured current. The channel diameter $D_{\mathrm{t}}(\mathrm{nm})$ at a given current $I_{\mathrm{t}}(\mathrm{A})$ can be estimated as follows.

$$
D_{\mathrm{t}}=1.3 \times 10^{3} I_{\mathrm{t}}^{0.5}
$$

At an etching time of $1,000 \mathrm{~s}, I_{\mathrm{t}}$ is around $2.5 \times 10^{-2}$ A and $D_{\mathrm{t}}$ is estimated to be of the order of 200 nm.

\subsection{Electrodeposition of Nanowires}

Figure 6 shows the effect of the cathode potential on the time-dependence of the cathodic current 
during Co-Cu alloy nanowire deposition in the polycarbonate template with channel length $30 \mu \mathrm{m}$ and diameter $200 \mathrm{~nm}$. The cathode potentials were fixed to $-0.7,-0.9,-1.1$, and $-1.3 \mathrm{~V}$. To determine the wire growth rate, the channel-filling time was estimated by monitoring the deposition current. When the wires reach the membrane surface, the current will increase drastically due to the formation of hemispherical caps. If the radius of a hemispherical cap increases linearly with increase in deposition time, the current increases in proportion to the square of deposition time because the current linearly depends on the surface area of a hemispherical cap. Deposition rates were estimated by dividing channel length by channel-filling time. At $-0.7 \mathrm{~V}$, this time is around $600 \mathrm{~s}$ and the deposition rate is estimated to be about $50 \mathrm{~nm} \mathrm{~s}^{-1}$, while the filling time is close to 60 $\mathrm{s}$ at $-1.3 \mathrm{~V}$ and the deposition rate is estimated to be around $500 \mathrm{~nm} \mathrm{~s}^{-1}$.

Figure 7(a) shows a cathodic polarization curve of polycarbonate template with channel length 30 $\mu \mathrm{m}$ and diameter $200 \mathrm{~nm}$. The growth rate of $\mathrm{Co}-\mathrm{Cu}$ alloy nanowires electrodeposited at each cathode potential is also shown in Fig.7(b). The equilibrium potentials of $\mathrm{Cu}$ and Co are estimated to be around $+0.05 \mathrm{~V}$ and $-0.48 \mathrm{~V}$ (vs. $\mathrm{Ag} / \mathrm{AgCl}$ ) on the basis of the Nernst equation as follows.

$$
E^{e q}=E^{0}+R T(n F)^{-1} \ln C_{M}
$$

Here, $E^{0}$ is the standard electrode potential, and $C_{M}$ denotes the concentration of metal ions $\left(\mathrm{Cu}^{2+}\right.$ or $\left.\mathrm{Co}^{2+}\right)$. The cathodic current occurs at the potential region close to the equilibrium potential of $\mathrm{Cu}$ as shown in Fig.7(a). It is well-known that $\mathrm{Cu}^{2+}$ ions begin to electrodeposit without an accompanying overpotential from the aqueous solution. Therefore, this cathodic current corresponds to the deposition current of $\mathrm{Cu}$. With increasing cathodic current, at around $10^{-5} \mathrm{~A}$, the potential significantly polarizes to the less-noble region. This phenomenon seems to be caused by the diffusion control of $\mathrm{Cu}^{2+}$ ions. In the potential region less-noble than the equilibrium potential of Co, the cathodic current increases again at circa $-0.8 \mathrm{~V}$. It is also well-known that the electrodeposition of iron-group metals such as $\mathrm{Ni}$, Co, and $\mathrm{Fe}$ is accompanied by the overpotential $[22,23]$ due to the rate determining multi-step reduction mechanism [24]. Therefore, this increase in cathodic current is mainly caused by the deposition current of Co. As depicted in Fig.7(b), the 
potential dependence of growth rate for the nanowires corresponds well to the polarization curve for $\mathrm{Cu}$ and Co deposition. On the basis of the results shown in Fig.7, the optimum deposition potentials of $\mathrm{Cu}$ and $\mathrm{Co}$ are determined to be about -0.3 and $-1.0 \mathrm{~V}$ (vs. $\mathrm{Ag} / \mathrm{AgCl}$ ), that is, at potentials nobler than the diffusion control region of each metal ion. Typical deposition rates of $\mathrm{Cu}$ and Co were roughly $20 \mathrm{~nm} \mathrm{~s}^{-1}$ (at $-0.3 \mathrm{~V}$ ) and $200 \mathrm{~nm} \mathrm{~s}^{-1}$ (at $-1.0 \mathrm{~V}$ ).

\subsection{Magnetoresistance of Nanowires}

Figure 8 exhibits the magnetoresistive hysteresis of $\mathrm{Co}-\mathrm{Cu}$ alloy nanowires electrodeposited at -1.0 $\mathrm{V}$ in a polycarbonate template with channel length $30 \mu \mathrm{m}$ and diameter $200 \mathrm{~nm}$. Here, $\theta$ is defined as the angle between the magnetic field and the nanowire axis (current direction). The MR ratio is defined by the following equation

$$
\text { MR ratio }(\%)=100\left(R_{0}-R_{10}\right) / R_{10}
$$

Here, $R_{0}$ and $R_{10}$ are the resistance of zero field and $10 \mathrm{kOe}$, respectively. AMR curves show the usual dependence on the direction of the applied magnetic field. In the direction parallel to the wire (0 deg), the effect of magnetic field on the resistance was very small and the MR ratio was almost zero, while in the direction perpendicular to the wire (90 deg), the MR effect was maximum. An AMR ratio of $0.6 \%$ was observed for $\mathrm{Co}_{81} \mathrm{Cu}_{19}$ alloy wires, which is typical of this system.

Figure 9 shows the magnetoresistive hysteresis of $\mathrm{Co} / \mathrm{Cu}$ multilayered wires electrodeposited in polycarbonate film. The wire length is $30 \mu \mathrm{m}$ and the diameter is $200 \mathrm{~nm}$. The layer thickness of Co and $\mathrm{Cu}$ amounts to $10 \mathrm{~nm}$. The structure of $\mathrm{Co} / \mathrm{Cu}$ nanowires electrodeposited in polymer templates is illustrated schematically in Fig. 9. GMR strongly depends on Co and Cu layer thickness, and a maximum effect could be observed at about $10 \mathrm{~nm}$ [11]. Therefore, a thickness of $10 \mathrm{~nm}$ was realized for each layer by controlling the deposition time. The GMR curves of Co/Cu multilayered nanowires possess only a small angular dependence, and the MR ratio reaches up to $8.0 \%$. For these samples, the saturation field seems to be around $5 \mathrm{kOe}$, which is much smaller than the field from which the AMR curves of Co-Cu alloy nanowires result. We have already reported that in porous alumina membranes $\mathrm{Co} / \mathrm{Cu}$ nanowires containing 100 and 300 bi-layers showed 20\% and 
$12 \%$ of GMR ratio [11], respectively, while the $\mathrm{Co} / \mathrm{Cu}$ nanowires containing 1,500 bi-layers showed $8.0 \%$ in this study. It is not surprising that the GMR ratio of $\mathrm{Co} / \mathrm{Cu}$ nanowires will decrease when increasing the number of bi-layers. For example, this GMR decrease could be caused by the enhancement of $\mathrm{Co} / \mathrm{Cu}$ interfacial roughness with increasing the number of bi-layers.

\section{CONCLUSION}

Heavy ion tracks in polycarbonate films were selectively etched using a $6 \mathrm{M}$ aqueous solution of $\mathrm{NaOH}$ to produce cylindrical nanochannels. The etching rate parallel to the ion track direction was estimated to be around $50 \mathrm{~nm} \mathrm{~s}^{-1}$. The channel diameters were tuned between 200 and $600 \mathrm{~nm}$ by varying the etching time, and the etching rate perpendicular to the ion track direction was estimated to be of the order of $0.2 \mathrm{~nm} \mathrm{~s}^{-1}$. Co-Cu alloy nanowires and $\mathrm{Co} / \mathrm{Cu}$ multilayered nanowires were successfully electrodeposited. The typical Cu deposition rate was about $20 \mathrm{~nm} \mathrm{~s}^{-1}$ at the cathode potential of $-0.3 \mathrm{~V}$, while the deposition rate of Co-rich alloy was circa $200 \mathrm{~nm} \mathrm{~s}^{-1}$ at $-1.0 \mathrm{~V}$. Corich alloy electrodeposited at -1.0V consisted of 81\%-Co and 19\%-Cu. Alternating Cu- and Co-rich layers of thickness $10 \mathrm{~nm}$ were synthesized by pulse plating. $0.6 \%$ of AMR on Co-Cu alloy nanowires and $8.0 \%$ of $\mathrm{GMR}$ on $\mathrm{Co} / \mathrm{Cu}$ nanowires were demonstrated for magnetic sensor applications.

\section{ACKNOWLEDGEMENTS}

This work was supported in part by the European Network on Ion Track Technology (EuNITT, HPRN-CT-2000-00047), Mitutoyo Association for Science \& Technology (MAST), Yazaki Memorial Foundation for Science \& Technology, Research Foundation for Materials Science, Japan

Society for the Promotion of Science (Grant-in-aid for Young Scientists B : No.17760581 and Grant-in-aid for Scientific Research C : No.19560734), and Nanotechnology Researchers Network Center of Japan (Japan-Sweden Young Researchers Exchange Program on Nanotechnology, 2006). 


\section{REFERENCES}

1) Martin C R (1991) Adv Mater 3:457

2) Whitney T M, Jiang J S, Searson P C, Chien C L (1993) Science 261:1316

3) Martin C R (1994) Science 266:1961

4) Piraux L, George J M, Despres J F, Leroy C, Ferain E, Legras R, Ounadjela K, Fert A (1994) Appl Phys Lett 65:2484

5) Blondel A, Meier J P, Doudin B, Ansermet J P (1994) Appl Phys Lett 65:3019

6) Evans P R, Yi G, Schwarzacher W (2000) Appl Phys Lett 76:481

7) Aimawlawi D, Coombs N, Moskovits M (1991) J Appl Phys 70:4421

8) Forrer P, Schlottig F, Siegenthaler H, Textor M (2000) J Appl Electrochem 30:533

9) Nielsch K, Müller F, Li A P, Gösele U (2000) Adv Mater 12:582

10) Ohgai T, Hoffer X, Gravier L, Wegrowe J E, Ansermet J P (2003) Nanotechnology 14:978

11) Ohgai T, Hoffer X, Fabian A, Gravier L, Ansermet J P (2003) J Mater Chem 13:2530

12) Ohgai T, Gravier L, Hoffer X, Lindeberg M, Hjort K, Spohr R, Ansermet J P (2003) J Phys D: Appl Phys 36:3109

13) Dobrev D, Vetter J, Angert N, Neumann R (1999) Appl Phys A: Mater Sci Process 69:233

14) Siwy Z, Dobrev D, Neumann R, Trautmann C, Voss K (2003) Appl Phys A: Mater Sci Process $76: 781$

15) Siwy Z, Apel P, Baur D, Dobrev D, Korchev Y E, Neumann R, Spohr R, Trautmann C, Voss K (2003) Surf Sci 532-535:1061

16) Enculescu I, Siwy Z, Dobrev D, Trautmann C, Toimil Molares M E, Neumann R, Hjort K, Westerberg L, Spohr R (2003) Appl Phys A: Mater Sci Process 77:751

17) Chtanko N, Toimil Molares M E, Cornelius T, Dobrev D, Neumann R (2004) J Phys Chem B 108:9950

18) Dobrev D, Baur D, Neumann R (2005) Appl Phys A: Mater Sci Process 80:451

19) Apel P, Akimenko A, Blonskaya I, Cornelius T, Neumann R, Schwartz K, Sphor R, Trautmann 
C (2006) Nucl Instr Meth B 245:284

20) Chtanko N, Toimil Molares M E, Cornelius T, Dobrev D, Neumann R (2005) Nucl Instr Meth B 236:103

21) Pépy G, Boesecke P, Kuklin A, Manceau E, Schiedt B, Siwy Z, Toulemonde M, Trautmann C (2007) J Appl Cryst 40:388

22) Tsuru T, Kobayashi S, Akiyama T, Fukushima H, Gogia S K, Kammel R (1997) J Appl Electrochem 27:209

23) Ohgai T, Enculescu I, Zet C, Westerberg L, Hjort K, Spohr R, Neumann R (2006) J Appl Electrochem 36:1157

24) Bockris J O’M, Kita H (1961) J Electrochem Soc 108:676 


\section{Captions}

Fig. 1. Schematic of fabrication process of $\mathrm{Co} / \mathrm{Cu}$ multilayered nanowires electrodeposited in nanochannels obtained by heavy-ion-track etching: (a) preparing latent tracks using heavy-ion beams, (b) etching of latent tracks leading to channels, (c) sputtering a gold layer on both sides of the surface and electrodeposition of $\mathrm{Cu}$ layer on the sputtered gold layer, (d) electrodeposition of $\mathrm{Co} / \mathrm{Cu}$ nanowires in the channels.

Fig. 2. Effect of film thickness on measured current during etching process in $6 \mathrm{M}$ aqueous solution of $\mathrm{NaOH}$ at $323 \mathrm{~K}$. The film thicknesses were 10, 30, and $60 \mu \mathrm{m}$.

Fig. 3. Relationship between polycarbonate film thickness and break-through time for preparing channels in $6 \mathrm{M}$ aqueous solution of $\mathrm{NaOH}$ at a temperature of $323 \mathrm{~K}$.

Fig. 4. SEM images of etched nanochannels in polycarbonate films with thickness $30 \mu \mathrm{m}$ obtained at etching time 1000, 1500, 2000, and 3000 s for (a) - (d), respectively.

Fig. 5. Time dependence of channel diameter (a), cross sectional area of channel (b), and measured current (c), during ion-track etching of a polycarbonate film with thickness $30 \mu \mathrm{m}$ in $6 \mathrm{M} \mathrm{NaOH}$ solution.

Fig. 6. Effect of cathode potential on measured current during Co-Cu alloy nanowire deposition in a polycarbonate template with channel length $30 \mu \mathrm{m}$ and diameter $200 \mathrm{~nm}$. The cathode potentials were $-0.7,-0.9,-1.1$, and $-1.3 \mathrm{~V}$.

Fig. 7. Cathodic polarization (a) and growth rate (b) of Co-Cu alloy nanowires, both as a function of applied cathode potential during electrodeposition in a polycarbonate template with channel length $30 \mu \mathrm{m}$ and diameter $200 \mathrm{~nm}$.

Fig. 8. Magnetoresistance of Co-Cu alloy nanowires with length $30 \mu \mathrm{m}$ and diameter $200 \mathrm{~nm}$ electrodeposited into polycarbonate nanochannels.

Fig. 9. Magnetoresistance of $\mathrm{Co} / \mathrm{Cu}$ multilayered nanowires with length $30 \mu \mathrm{m}$ and diameter 200 $\mathrm{nm}$ electrodeposited in polycarbonate nanochannels. The layer thickness of Co and Cu is $10 \mathrm{~nm}$. 
(a) Heary Ion Tracking

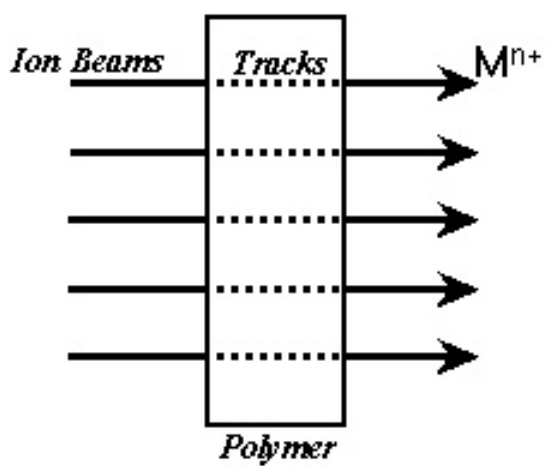

(c) Formation of Electrodes

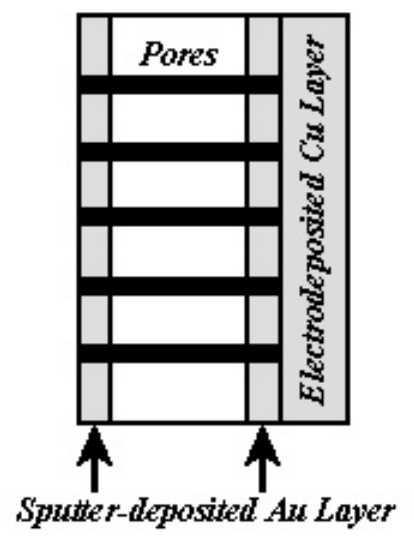

(b) Etching of Through Pores

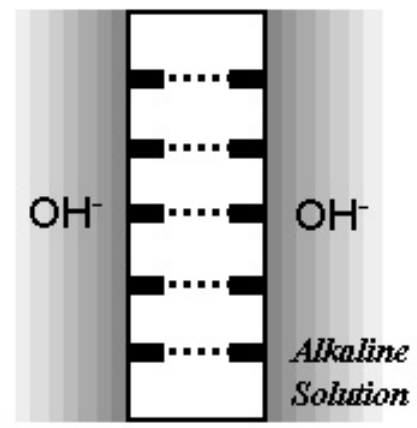

(d) Electrodeposition of Co/Cu

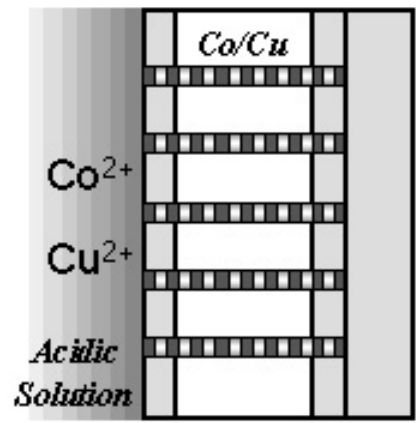

Fig. 1. Schematic of fabrication process of $\mathrm{Co} / \mathrm{Cu}$ multilayered nanowires electrodeposited in nanochannels obtained by heavy-ion-track etching: (a) preparing latent tracks using heavy-ion beams, (b) etching of latent tracks leading to channels, (c) sputtering a gold layer on both sides of the surface and electrodeposition of $\mathrm{Cu}$ layer on the sputtered gold layer, (d) electrodeposition of $\mathrm{Co} / \mathrm{Cu}$ nanowires in the channels. 


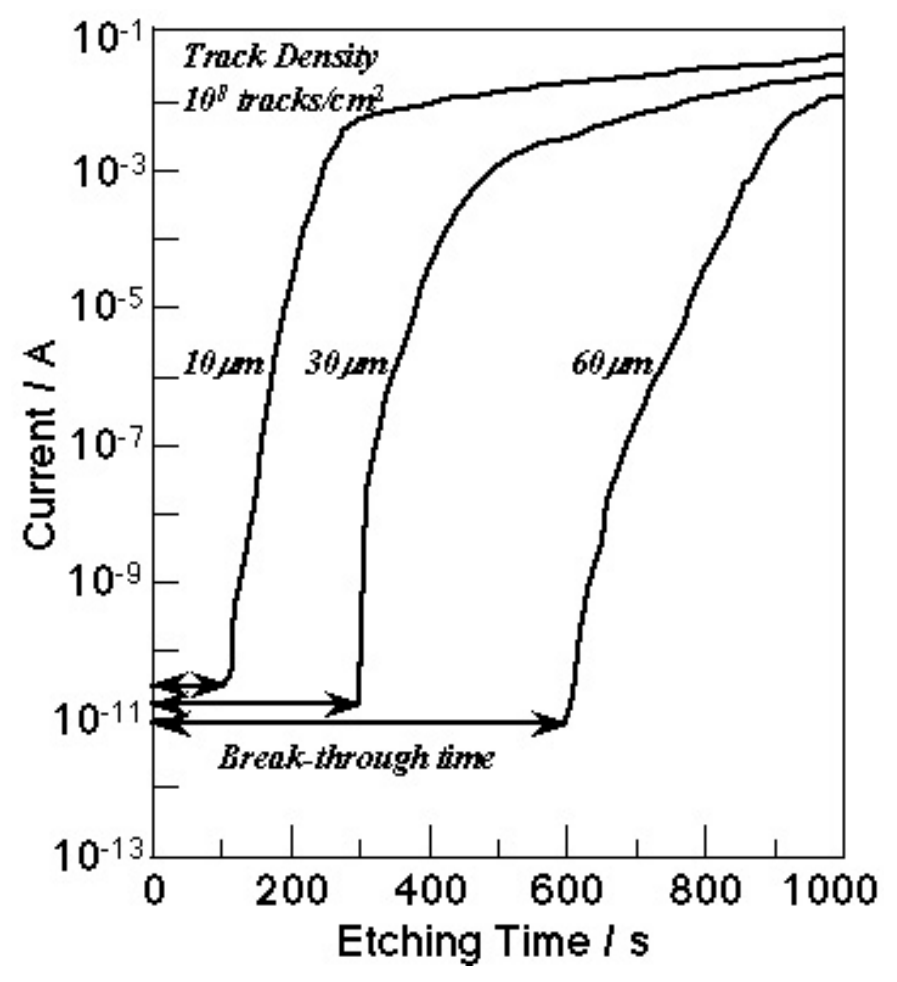

Fig. 2. Effect of film thickness on measured current during etching process in $6 \mathrm{M}$ aqueous solution of $\mathrm{NaOH}$ at $323 \mathrm{~K}$. The film thicknesses were 10, 30, and $60 \mu \mathrm{m}$. 


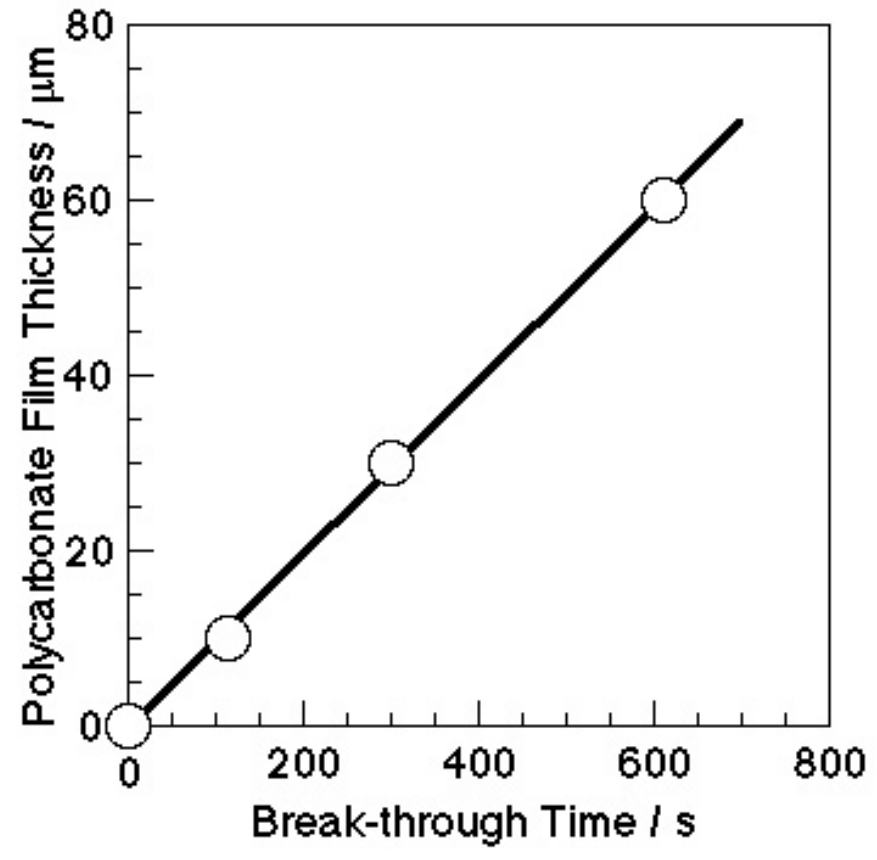

Fig. 3. Relationship between polycarbonate film thickness and break-through time for preparing channels in $6 \mathrm{M}$ aqueous solution of $\mathrm{NaOH}$ at a temperature of $323 \mathrm{~K}$. 


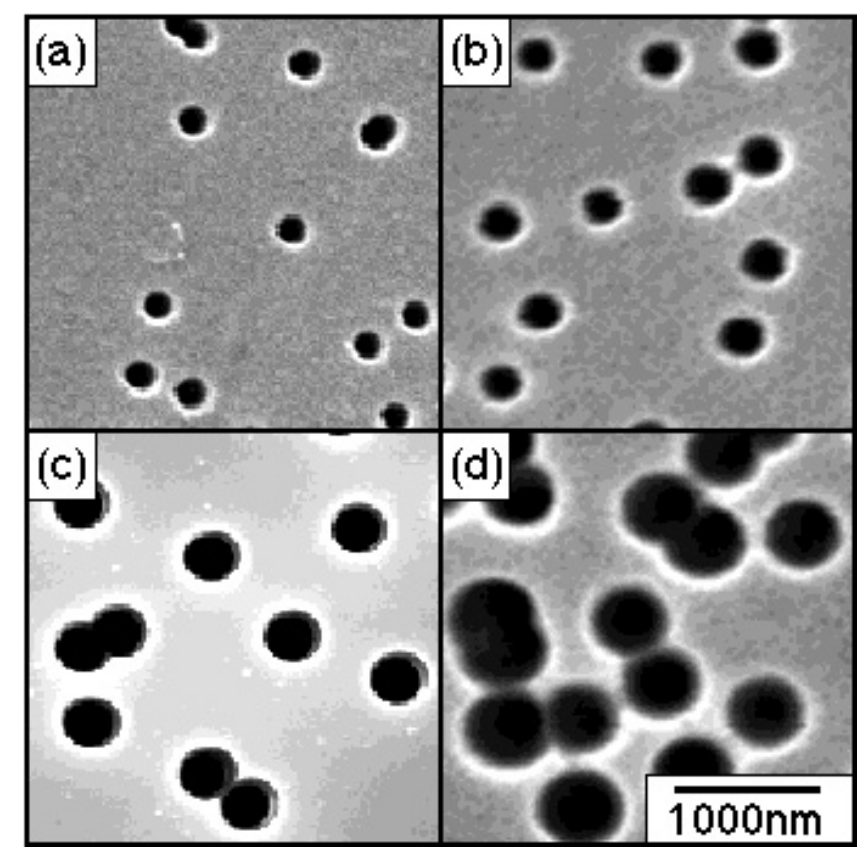

Fig. 4. SEM images of etched nanochannels in polycarbonate films with thickness $30 \mu \mathrm{m}$ obtained at etching time 1000, 1500, 2000, and $3000 \mathrm{~s}$ for (a) - (d), respectively. 


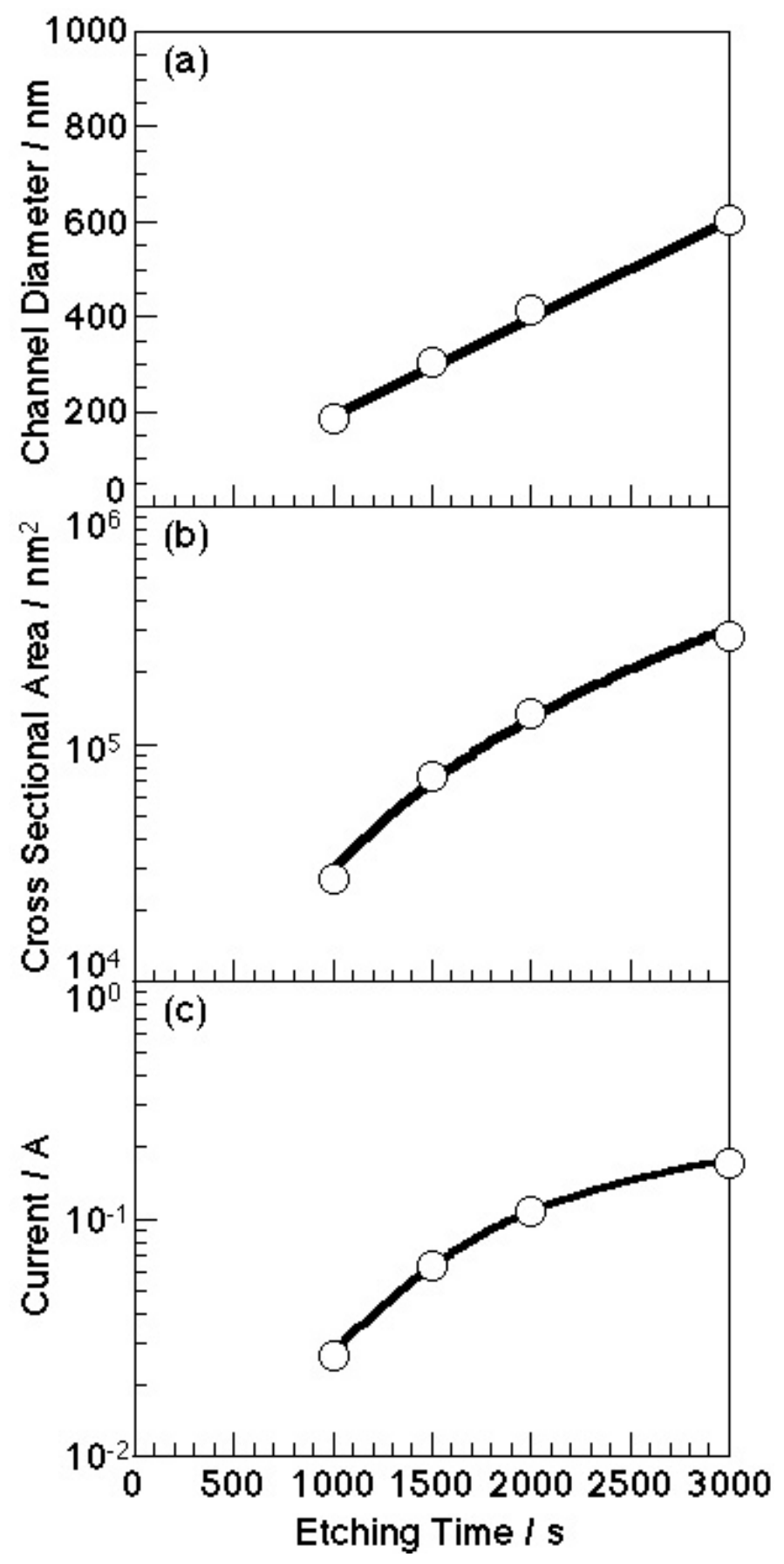

Fig. 5. Time dependence of channel diameter (a), cross sectional area of channel (b), and measured current (c), during ion-track etching of a polycarbonate film with thickness $30 \mu \mathrm{m}$ in $6 \mathrm{M} \mathrm{NaOH}$ solution. 


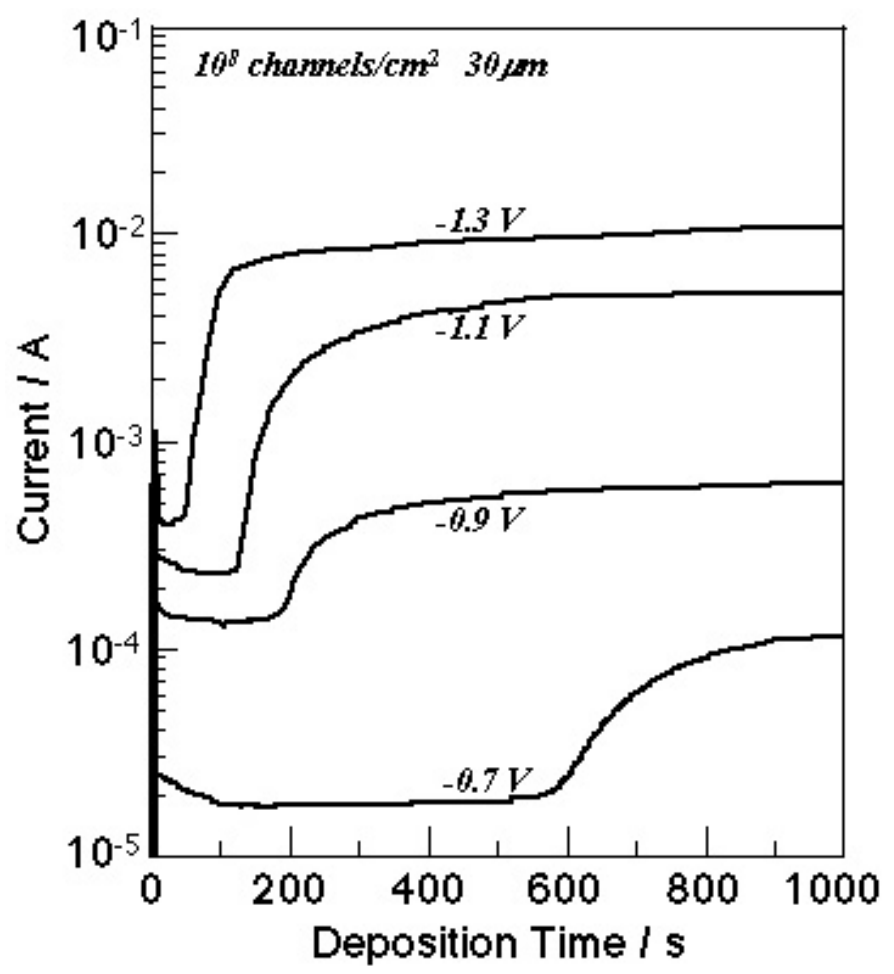

Fig. 6. Effect of cathode potential on measured current during $\mathrm{Co}-\mathrm{Cu}$ alloy nanowire deposition in a polycarbonate template with channel length $30 \mu \mathrm{m}$ and diameter $200 \mathrm{~nm}$. The cathode potentials were $-0.7,-0.9,-1.1$, and $-1.3 \mathrm{~V}$. 


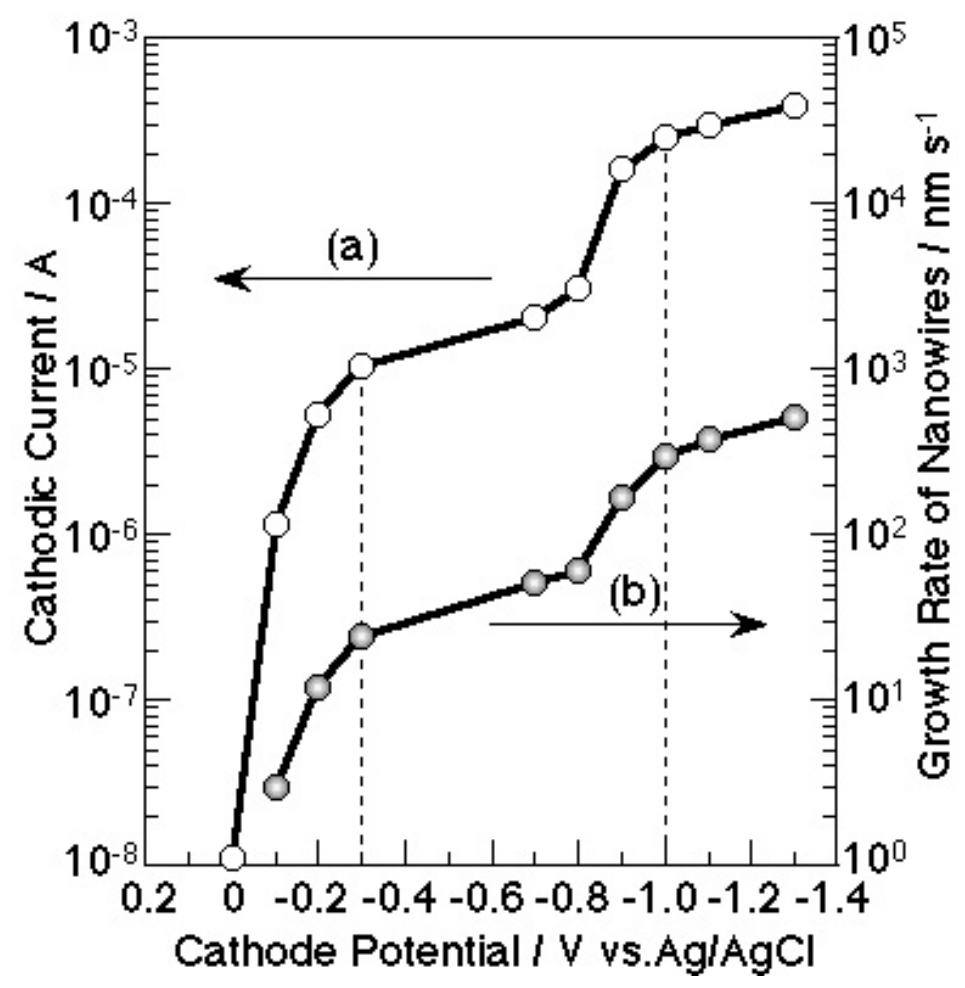

Fig. 7. Cathodic polarization (a) and growth rate (b) of Co-Cu alloy nanowires, both as a function of applied cathode potential during electrodeposition in a polycarbonate template with channel length $30 \mu \mathrm{m}$ and diameter $200 \mathrm{~nm}$. 


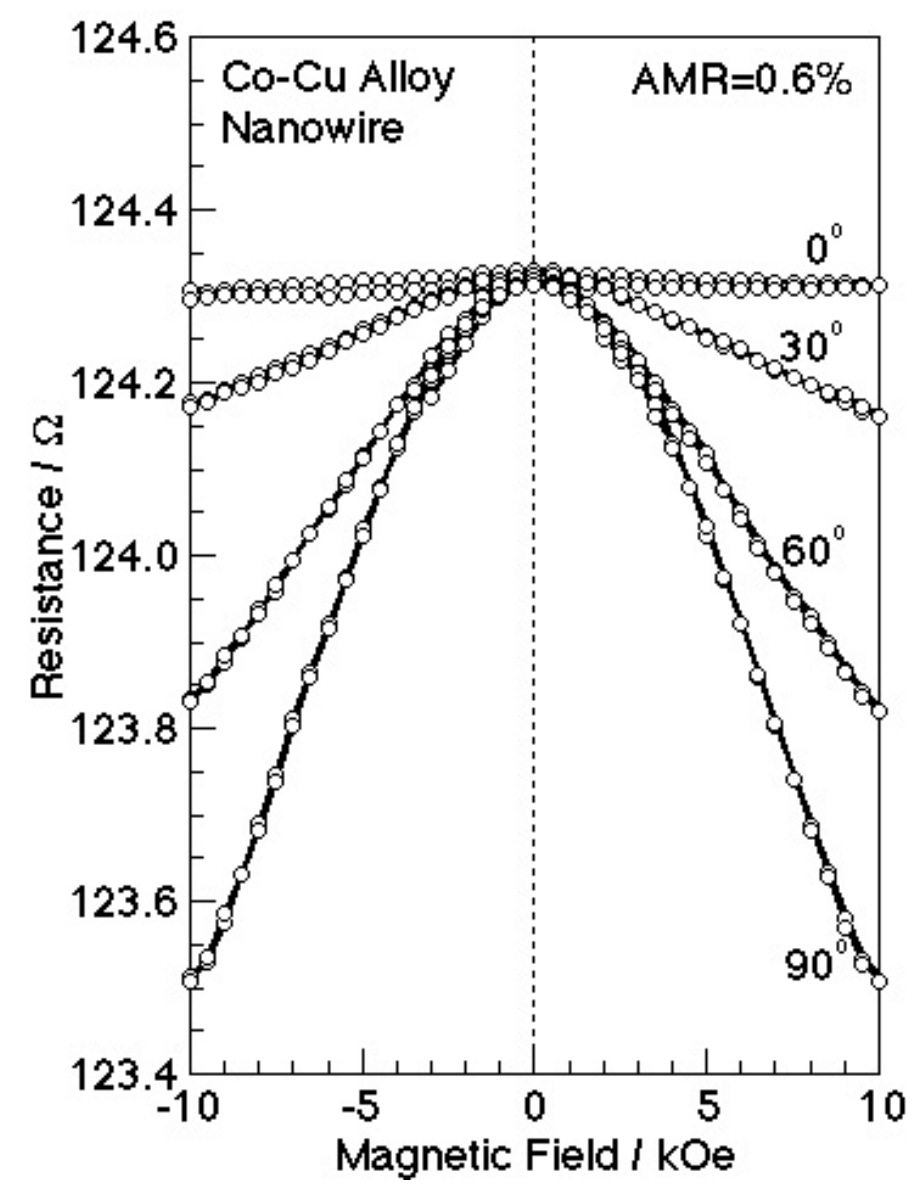

Fig. 8. Magnetoresistance of Co-Cu alloy nanowires with length $30 \mu \mathrm{m}$ and diameter $200 \mathrm{~nm}$ electrodeposited into polycarbonate nanochannels. 


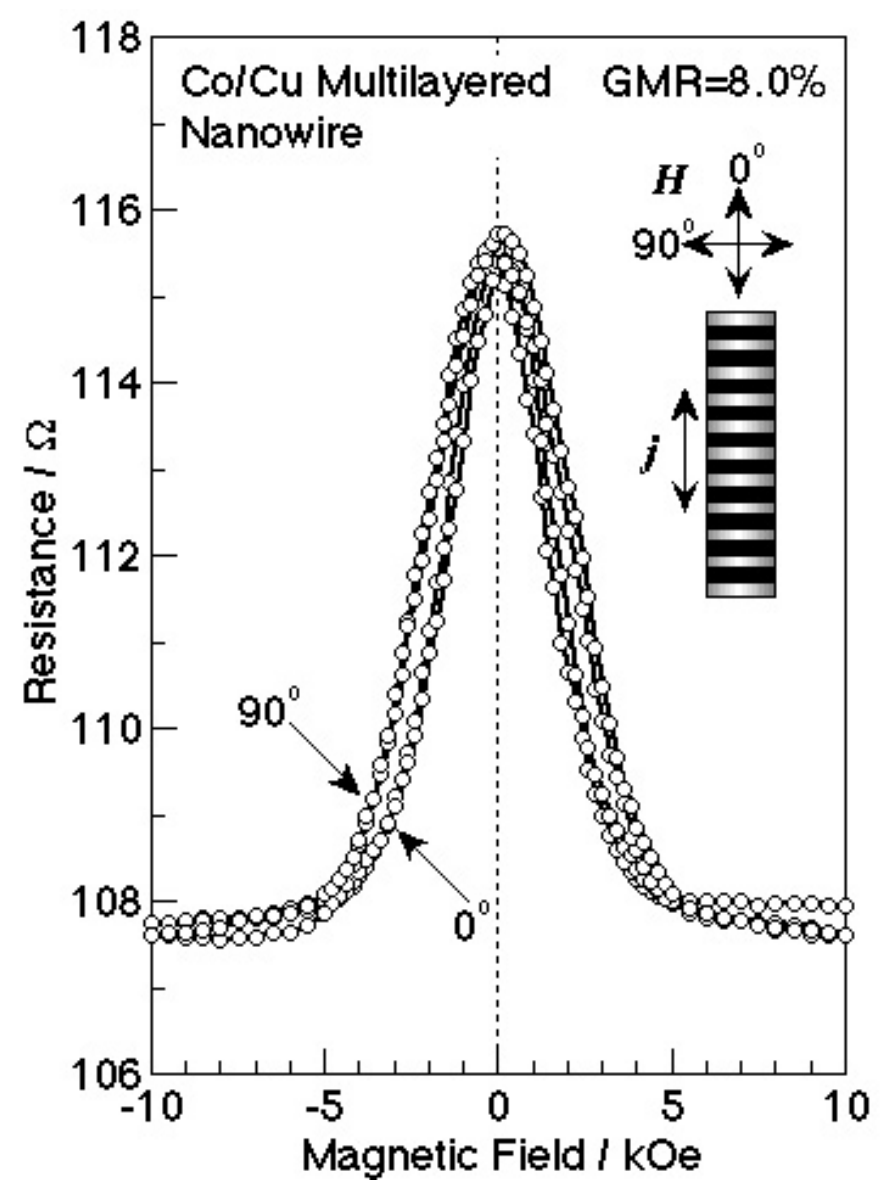

Fig. 9. Magnetoresistance of $\mathrm{Co} / \mathrm{Cu}$ multilayered nanowires with length $30 \mu \mathrm{m}$ and diameter 200 $\mathrm{nm}$ electrodeposited in polycarbonate nanochannels. The layer thickness of Co and $\mathrm{Cu}$ is $10 \mathrm{~nm}$. 